\title{
Cu K-absorption edge study of cuprate superconductors ${ }^{\dagger}$
}

\author{
G SANKAR*, G U KULKARNI and K R KANNAN \\ Solid State and Structural Chemistry Unit, Indian Institute of Science, Bangalore 560012 , \\ India
}

MS received 28 April 1989

\begin{abstract}
Cu} \mathrm{K}$-absorption edges of $\mathrm{YBa}_{2} \mathrm{Cu}_{3} \mathrm{O}_{6,9}, \mathrm{Tl}_{2} \mathrm{CaBa}_{2} \mathrm{Cu}_{2} \mathrm{O}_{8}$ and $\mathrm{Bi}_{2} \mathrm{CaSr}_{2} \mathrm{Cu}_{2} \mathrm{O}_{8}$ show similar features. Copper is mainly in the $2+$ state in these cuprates suggesting the likely presence of oxygen holes.
\end{abstract}

Keywords. Superconductivity; layered cuprates.

PACS No. $\mathbf{7 4 \cdot 7 0}$

K-absorption edge spectroscopy of copper has been employed to investigate the new cuprate superconductors by a few workers. The general conclusion is that there is no $\mathrm{Cu}^{3+}$ in $\mathrm{YBa}_{2} \mathrm{Cu}_{3} \mathrm{O}_{7}$ (Chakraverty et al 1988; Fuggle et al 1988; Rao 1988; Rao et al 1989a). These measurements also show a feature at $21 \mathrm{eV}$ above the absorption edge (taken with respect to the $1 s-3 d$ pre-edge shoulder) which was suspected for sometime to be due to $\mathrm{Cu}^{3+}$ by some workers. We have investigated $\mathrm{Cu} \mathrm{K}$-edge spectra of cuprate superconductors belonging to different families to see commanalities, if any, and to understand the important features.

$\mathrm{YBa}_{2} \mathrm{Cu}_{3} \mathrm{O}_{6.9}, \mathrm{Tl}_{2} \mathrm{CaBa}_{2} \mathrm{Cu}_{2} \mathrm{O}_{8}$ and $\mathrm{Bi}_{2} \mathrm{CaSr}_{2} \mathrm{Cu}_{2} \mathrm{O}_{8}$ were prepared by the procedures described in the literature. $\mathrm{Cu} \mathrm{K}$-edge $\mathrm{X}$-ray absorption spectra were recorded using a commercially available X-ray absorption spectrometer (Rigaku, Japan) attached to a $12 \mathrm{~kW}$ rotating anode $\mathrm{X}$-ray generator with a copper target and $\mathrm{Ge}(333)$ was employed as the monochromatizing crystal. The spectrometer was calibrated using the characteristic emission lines of copper target $K \alpha_{1}$ or $K \alpha_{2}$ appearing at 8.04778 and $8.02778 \mathrm{keV}$. The energy resolution at this energy was found to be better than $2 \mathrm{eV}$. The appropriate amount of powdered samples was sandwiched between adhesive tapes for the $\mathrm{Cu} \mathrm{K}$-edge absorption measurement. Measurements were carried out between 8.97 and $9.02 \mathrm{keV}$ in steps of $0.1 \mathrm{eV}$ and repeated several times to confirm the presence of various features appearing in the spectra.

In figure 1 we show the normalized $\mathrm{Cu} \mathrm{K}$-edge spectra of the reference materials $\mathrm{Cu}$ metal, $\mathrm{Cu}_{2} \mathrm{O}$ and $\mathrm{CuO}$ representing $\mathrm{Cu}^{0}, \mathrm{Cu}^{1+}$ and $\mathrm{Cu}^{2+}$ oxidation states respectively. The spectral features in these systems clearly show expected variation with the oxidation state. In $\mathrm{CuO}$, the pre-edge feature, generally considered to be due to the $1 s-3 d$ transition, appears at $8.982 \mathrm{keV}$ followed by a main peak at $8.997 \mathrm{keV}$ with a shoulder around $8.987 \mathrm{keV} . \mathrm{Cu}_{2} \mathrm{O}$, on the other hand, shows a well-defined

\footnotetext{
${ }^{\dagger}$ Contribution No 616 from the Solid State and Structural Chemistry Unit.

* To whom correspondence should be addressed.
} 


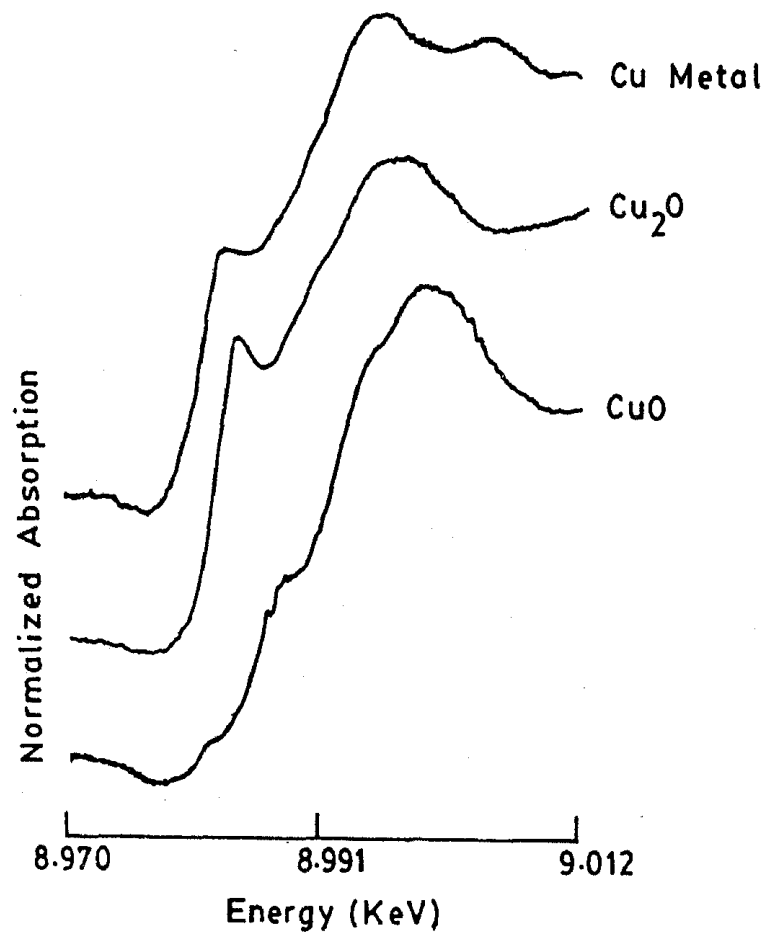

Figure 1. Normalized $\mathrm{Cu}$ K-edge XANES of $\mathrm{Cu}$ metal, $\mathrm{Cu}_{2} \mathrm{O}$ and $\mathrm{CuO}$.

feature at $8.983 \mathrm{keV}$ due to a symmetry related transition, followed by the main peak. The $8.983 \mathrm{keV}$ feature is characteristic of $\mathrm{Cu}^{1+}$ species in oxide systems while the shoulder at $8.987 \mathrm{keV}$ (of $\mathrm{CuO}$ ) has been used to characterize the $\mathrm{Cu}^{2+}$ state (Rao et al 1989b; Tranquada et al 1988).

In figure 2 we show XANES of $\mathrm{YBa}_{2} \mathrm{Cu}_{3} \mathrm{O}_{6.9}, \mathrm{Tl}_{2} \mathrm{CaBa}_{2} \mathrm{Cu}_{2} \mathrm{O}_{8+\delta}$ and $\mathrm{Bi}_{2} \mathrm{CaSr}_{2} \mathrm{Cu}_{2} \mathrm{O}_{8+\delta}$. All these cuprates show feature at $8.987 \mathrm{keV}$ characteristic of $\mathrm{Cu}^{2+}$ as in $\mathrm{CuO}$. The main peak position also clearly suggests that the predominant oxidation state of $\mathrm{Cu}$ in these high $T_{c}$ cuprates is $2+$. There is no evidence for $\mathrm{Cu}^{3+}$ in any of these cuprates. The pre-edge intensity is however slightly different compared to $\mathrm{CuO}$. A systematic investigation of XANES of mixtures of $\mathrm{Cu}_{2} \mathrm{O}$ and $\mathrm{CuO}$ has shown that presence of $50 \%$ or more of $\mathrm{Cu}_{2} \mathrm{O}$ in the mixture is necessary to show the feature due to $\mathrm{Cu}^{1+}$ alongwith that of $\mathrm{Cu}^{2+}$. Lower than $50 \% \mathrm{Cu}_{2} \mathrm{O}$ does not show pre-edge feature at $8.983 \mathrm{keV}$. We are therefore not able to rule out the presence of $\mathrm{Cu}^{1+}$ in these cuprate systems. However, the concentration of $\mathrm{Cu}^{1+}$ in these cuprates is less than that in $\mathrm{Pb}_{2} \mathrm{Sr}_{2} \mathrm{Ca}_{1-x} \mathrm{Ln}_{x} \mathrm{Cu}_{3} \mathrm{O}_{\mathrm{B}+\delta}$ where the feature at $8.983 \mathrm{keV}$ due to $\mathrm{Cu}^{1+}$ clearly shows up in the $\mathrm{K}$-edge spectrum (Rao et al 1989b). The absence of $\mathrm{Cu}^{3+}$ and direct evidence for only $\mathrm{Cu}^{2+}$ in these cuprates suggests the presence of oxygen holes (Chakraverty et al 1988; Rao 1988).

Recent reports in the literature have proposed different explanations regarding the appearance of the $21 \mathrm{eV}$ feature (measured with respect to the pre-edge feature). One of the explanations is that this feature is due to $\mathrm{Cu}$ occupying the $\mathrm{Y}$ site (anti-site). This has been ruled out by an orientation dependence study and also based on configuration interaction calculations (Sarma 1988). A similar feature is seen at $5-6 \mathrm{eV}$ from the main absorption peak in simple transition metal halides (Stern 1982). This has been suggested as due to shake-up satellites associated with the main absorption. Our XANES measurement on simple oxides showed a similar feature at higher energy, 


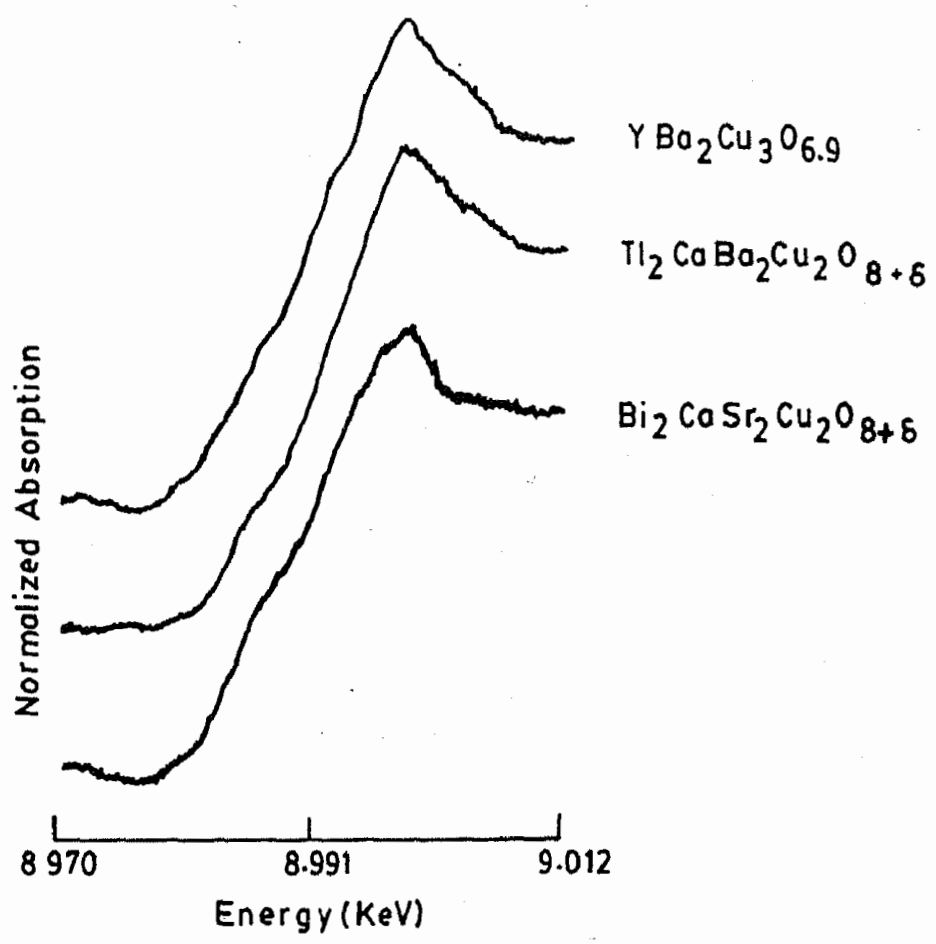

Figure 2. Normalized $\mathrm{Cu} \mathrm{K}$-edge XANES of high $\mathrm{T}_{c}$ superconducting oxides: $\mathrm{YBa}_{2} \mathrm{Cu}_{3} \mathrm{O}_{6.9}$, $\mathrm{Tl}_{2} \mathrm{CaBa}_{2} \mathrm{Cu}_{2} \mathrm{O}_{8+\delta}$ and $\mathrm{Bi}_{2} \mathrm{CaSr}_{2} \mathrm{Cu}_{2} \mathrm{O}_{8+\delta}$.

falling well below the EXAFS region which starts from about $40 \mathrm{eV}$ from the absorption edge. This feature probably therefore arises from satellite structure arising from configuration interaction (Sarma 1988).

\section{Acknowledgement}

The authors thank Prof C N R Rao for suggesting the problem and guidance. Their thanks are due to the Department of Science and Technology for support of this research.

\section{References}

Chakraverty B K, Sarma D D and Rao C N R 1988 Physica C156 413

Fuggle J C, Fink J and Nücker W 1988 Int. J. Mod. Phys. B1 1185

Tranquada J M, Heald S M, Moodenbaugh A R and Youwen Xu 1988 Phys. Rev. B38 8893

Lytle F W, Greegor R B and Panson A J 1988 Phys. Rev. B37 1550.

Rao C N R 1988 Mod. Phys. Lett. B2 1217

Rao C N R, Sarma D D, Ranga Rao G 1989a Phase transitions (in press)

Rao C N R, Bhat V, Nagarajan R, Ranga Rao G and Sankar G 1989 b Phys. Rev. B (in press)

Sarma D D 1988 Phys. Rev. B37 7948

Stern E A 1982 Phys. Rev. Lett. 491353 